\title{
Cloning and Characterization of an Esophageal-Gland- Specific Chorismate Mutase from the Phytoparasitic Nematode Meloidogyne javanica
}

\author{
Kris N. Lambert, Keith D. Allen, and lan M. Sussex \\ Department of Plant and Microbial Biology, University of California, Berkeley 94720, U.S.A. \\ Accepted 6 January 1999.
}

Root-knot nematodes are obligate plant parasites that alter plant cell growth and development by inducing the formation of giant feeder cells. It is thought that nematodes inject secretions from their esophageal glands into plant cells while feeding, and that these secretions cause giant cell formation. To elucidate the mechanisms underlying the formation of giant cells, a strategy was developed to clone esophageal gland genes from the root-knot nematode Meloidogyne javanica. One clone, shown to be expressed in the nematode's esophageal gland, codes for a potentially secreted chorismate mutase (CM). CM is a key branch-point regulatory enzyme in the shikimate pathway and converts chorismate to prephenate, a precursor of phenylalanine and tyrosine. The shikimate pathway is not found in animals, but in plants, where it produces aromatic amino acids and derivative compounds that play critical roles in growth and defense. Therefore, we hypothesize that this $\mathrm{CM}$ is involved in allowing nematodes to parasitize plants.

Root-knot nematodes (Meloidogyne spp.) are obligate plant parasites that infect most cultivated plants (Sasser 1980). The second-stage juvenile (J2) is the infectious stage of root-knot nematodes. The J2 nematode migrates through the soil and penetrates the host plant root in the zone of elongation. The J2 migrates between plant cells until it reaches the developing vascular tissue, where it presumably injects secretions through its stylet into or around approximately six parenchyma cells. The affected plant cells undergo a dramatic transformation, becoming giant multinucleate cells on which the nematode nondestructively feeds throughout the rest of its life cycle (Williamson and Hussey 1996).

Secretions originating from the phytoparasitic nematode esophageal glands are thought to play key roles in host penetration, giant cell formation, and food digestion. Root-knot nematodes have three esophageal glands, one dorsal and two subventral. Each gland is a single enlarged cell that is specialized to export secretions into the nematode's esophageal

Corresponding author: Kris N. Lambert

E-mail: klambert@nature.berkeley.edu

Nucleotide and/or amino acid sequence data are to be found at the GenBank data base as accession numbers AF095949 and AF095950 for the NC30 cDNA and genomic clones, respectively. lumen. Once in the lumen the secretions from the glands may either move out of the nematode via the stylet or pass into the nematode's intestine (Doncaster 1971). The subventral glands are thought to produce pectinases and cellulases that assist the nematode in penetrating the host root (Bird et al. 1974; Dropkin 1963). Recently, this hypothesis has been confirmed by the identification of several genes encoding cellulases that are expressed in the subventral esophageal glands of cyst nematodes (Smant et al. 1998). The subventral glands may also be involved in the production of secretions that pass into the nematode's intestine and aid in the digestive process (Doncaster 1971). The dorsal esophageal gland is thought to be the source of nematode factors responsible for the maintenance of giant cells. Both types of glands may play a role in the initiation of giant cells (Hussey 1989). However, the role of the esophageal gland secretions in phytoparasitic nematode parasitism is largely theoretical since few gland genes have been cloned. In order to clarify the role of these glands we have initiated a project to identify esophageal-gland genes that encode secreted proteins.

To clone the gland genes, a cDNA library was constructed from the esophageal gland region of Meloidogyne javanica and differentially screened to identify genes expressed in the esophageal glands. One such gene encoded a chorismate mutase (CM; EC 5.4.99.5), an enzyme in the shikimate pathway.

The shikimate pathway is a primary metabolic route in plants and microorganisms. The end-product of the common shikimate pathway is chorismate, a branch-point metabolite that is the precursor for the three aromatic amino acids phenylalanine, tyrosine, and tryptophan. In plants, chorismatederived compounds (CDCs) are converted into a vast array of secondary metabolites that either are derived directly from chorismate or are formed from an aromatic amino acid (Strack 1997). These CDCs play critical roles in plant growth, development, and defense, and in interactions with other organisms (Schmid and Amrhein 1995; Weaver and Herrmann 1997).

CM catalyzes the conversion of chorismate to prephenate, providing the precursors for the synthesis of phenylalanine and tyrosine. This enzymatic reaction is unique since it is the only example in primary metabolism of a pericyclic Claisenrearrangement (Romero et al. 1995). Because CM is an unusual and essential enzyme, it has been studied extensively in many organisms; it is found in bacteria, fungi, plants, and protists, but not in animals (Roberts et al. 1998; Romero et al. 1995; Stryer 1988). It is commonly believed that animals do 
not have the shikimate pathway or CMs because they obtain their essential amino acids in their diet (Schmid and Amrhein 1995). While this is true for most animals, CM might still be useful to animals like phytoparasitic nematodes that have a close association with plants.

This paper describes an approach for isolating genes that are expressed specifically in the esophageal glands of nematodes. Using this approach, we have identified an esophagealgland-specific gene that encodes a potentially secreted CM. We hypothesize that this CM plays a role in allowing nematodes to parasitize plants.

\section{RESULTS}

\section{Gland-region cDNA library construction.}

It seems likely that $\mathrm{J} 2$ nematodes express esophageal gland genes that induce giant cell formation when they are attempting to establish feeding sites in roots. Therefore, individual J2 nematodes were dissected from tomato roots 5 days after inoculation. Nematodes in this stage are referred to as postinfection $\mathrm{J} 2$ nematodes. To enrich for expressed gland genes, the region containing the esophageal glands was microdissected from three post-infection J2 nematodes. The dissected nematode fragments were transferred to a microfuge tube and the cDNA was amplified with the polymerase chain reaction (PCR). Nematode cDNA library construction is greatly simplified because a subset of nematode mRNAs have a 22 base leader, called a spliced leader (SL), added to their $5^{\prime}$ ends. This sequence is added to about 70 to $90 \%$ of nematode primary transcripts by a trans-splicing process (Blumenthal 1995; Nilsen 1993). Although the percentage of primary transcripts in root-knot nematodes that are trans-spliced has not been determined, we assumed that the extent of trans-splicing was similar to that in other nematodes. The SL sequence has been exploited to facilitate PCR amplification of the transspliced subset of nematode RNAs (Martin et al. 1995). Using this principle, we amplified nematode cDNAs from microscopic amounts of RNA. Briefly, poly- $\mathrm{A}^{+}$nematode RNA was captured with a poly-dT tailed oligonucleotide attached to paramagnetic beads. Then, cDNA was synthesized by reverse transcriptase and the bead poly-dT primer. The nematode cDNA was amplified by PCR with a primer complementary to the SL sequence and a primer that hybridizes to the poly-dTtailed primer. This PCR method is simple, generates fulllength cDNAs, and only amplifies nematode cDNAs. The amplified gland-region cDNA was used to construct a library containing 3,800 primary transformants.

\section{Isolation of an esophageal gland-region cDNA.}

The gland-region cDNA library was differentially screened to isolate genes preferentially expressed in this area. The differential screening strategy used two different ${ }^{32} \mathrm{P}$-labeled cDNA probes isolated from post-infection $\mathrm{J} 2$ nematodes. One was derived from the dissected esophageal gland region and the other from a dissected region posterior to the gland region (tail region). Clones that hybridized strongly to the gland probe but not to the tail probe were considered excellent candidates for gland-specific genes.

Clones having the desired hybridization pattern were analyzed further by sequence analysis. Predicted protein sequences were analyzed for homologies to proteins in sequence data bases, the presence of signal sequences, and conserved sequence motifs. One clone, NC30, had significant similarity to a CM (BLASTP2, E-value 0.005, 30\% identical, 50\% similar) from the gram-negative bacterium Erwinia herbicola (Xia et al. 1993; Fig. 1). The predicted NC30 protein is 191 amino acids in length. The NC30 protein appears to have a signal sequence with a cleavage site between amino acids 22 and 23 (von Heijne and Abrahmsén 1989), indicating that the mature NC30 protein is 169 amino acids long or about 20 $\mathrm{kDa}$. A motif search (Bairoch et al. 1997) identified four possible N-glycosylation sites at amino acids 55, 77, 94, and 108, indicating that the NC30 protein could be a glycoprotein (Fig. 1). The NC30 protein was predicted to be extracellular by the subcellular-targeting prediction computer program PSORT (Nakai and Kanehisa 1992).

\section{Nematode origin of the $N C 30$ gene.}

Since the NC30 cDNA had homology to a bacterial sequence, it was important to confirm that it originated from nematode tissue. To determine if $N C 30$ would hybridize to nematode genomic DNA, the NC30 cDNA was radiolabeled and hybridized to Southern blots containing EcoRI-, ClaI-, and EcoRV-digested genomic DNA from $M$. javanica (Fig. $2 \mathrm{~A}$ and $\mathrm{B}$ ). The NC30 cDNA hybridized to three bands (1.6, 1.7 , and $2.1 \mathrm{~kb}$ ) in the EcoRI-digested nematode DNA. The lanes containing nematode DNA digested with ClaI and EcoRV also hybridized with three to four restriction fragments ranging from 2.5 to $15 \mathrm{~kb}$ in size (Fig. 2B). Since the NC30 cDNA hybridized to multiple bands and neither the probe or $N C 30$ genomic clone contains EcoRI or EcoRV sites, NC3O is apparently a member of a small multigene family. In Figure $2 \mathrm{~A}$ the hybridization intensity of the $1.6-\mathrm{kb}$ band is higher than that of the others. This indicates that there may be more than one copy of this $1.6-\mathrm{kb}$ restriction fragment in the genome or that the larger bands represent divergent NC3O genes.

While these hybridizations indicate that NC30 is a nematode gene, it is possible that the signal on the blot could have come from a bacterial contaminant in the nematode DNA preparation. For this reason, two identical Southern blots were made containing both nematode and tomato DNA. The blot in Figure $2 \mathrm{C}$ was hybridized with the $N C 30 \mathrm{cDNA}$ probe and the blot in Figure 2D was hybridized with a cDNA probe of a known nematode gene, sec-1 (Ray et al. 1994). Both probes were identical in concentration and specific activity. Each probe hybridized to the nematode DNA and not to the tomato DNA. The hybridization signal intensities for the NC3O and sec-1 probes were very similar, indicating that the number of copies per genome for the two genes are about equal. Since it is unlikely that a trace bacterial contaminant of the nematode DNA preparation would have the same number of copies per genome as a nematode gene, these data support the argument that $N C 30$ originates in the nematodes. To show that there was tomato DNA on the blot in Figure 2C, this filter was stripped then hybridized with the tomato cDNA LeMSI1 (Ach et al. 1997; Fig. 2E).

When we isolated and sequenced the NC30 genomic clone, we obtained further evidence that $N C 30$ is a nematode gene. We used a PCR-based approach to obtain the NC3O genomic clone. A 1-kb genomic clone was amplified by PCR from nematode genomic DNA with primers that flanked the $N C 30$ 
coding region (Fig. 3A). The DNA flanking the coding region was cloned by inverse PCR from EcoRI-cut genomic DNA (Fig. 3B). The inverse PCR amplification products showed four closely spaced bands from 1.4 to $2 \mathrm{~kb}$ in size, which is consistent with the Southern blot data in Figure 2A. We assumed that the 1.4-kb PCR product in Figure 3B was analogous to the $1.6-\mathrm{kb}$ restriction fragment in Figure 2A. Since this showed the strongest hybridization signal, it was chosen for cloning and sequencing along with the PCR product in Figure 3A. The assembled genomic sequence is shown in Figure 4A. When the $N C 30$ genomic sequence was compared with the NC3O cDNA, two introns were identified in the genomic clone (Fig. 4A). The 3' splice site in the second intron closely matched the consensus sequence of the

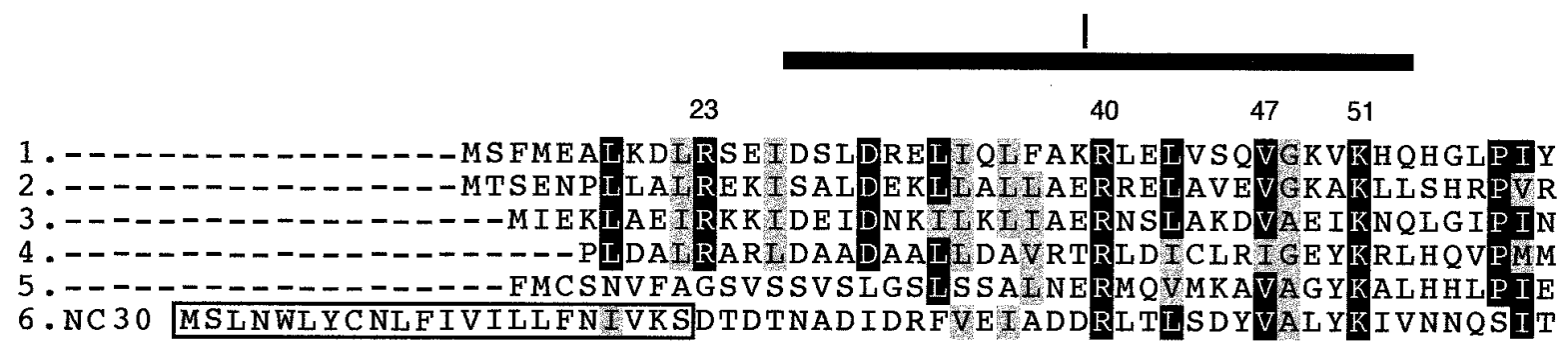

55

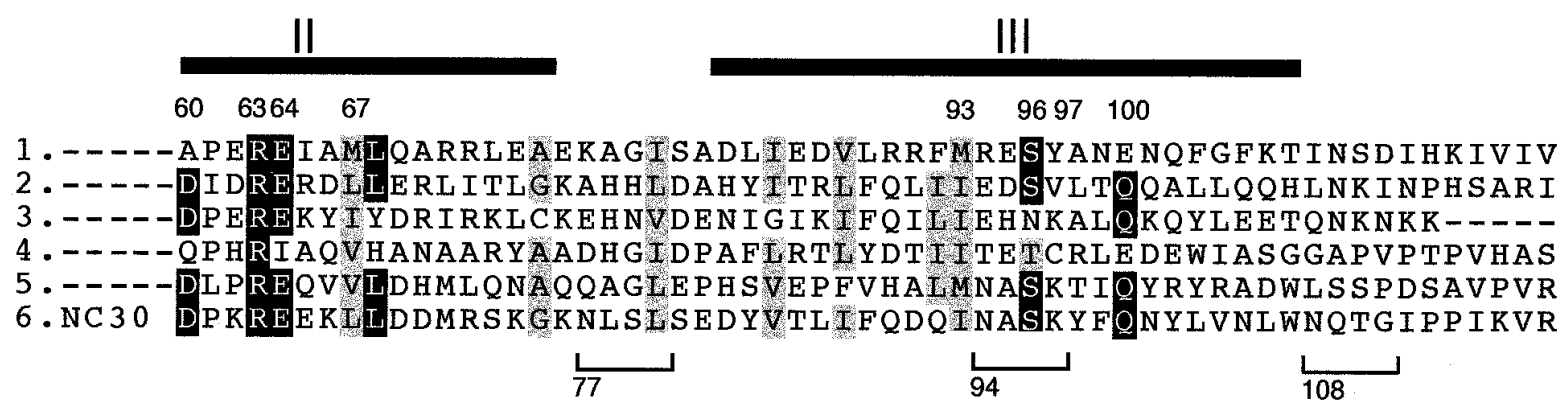

\section{6 . NC 30 NLNTDLRPAIDQINTEMLQLLVKIQKLPSKDCLKKVDKSVNNFIMRVNQIDEQNDALKMAVK}

Fig. 1. Multiple sequence alignment of the predicted NC30 protein sequence with the mutase domain of bacterial CMs (chorismate mutases). Putative signal sequence of the NC30 protein (sequence 6) is boxed. Numbered brackets indicate putative glycosylation sites. Numbers above the sequences indicate residues that contribute to the active site of the Escherichia coli CM (sequence 2) as determined by X-ray crystal structure analysis (Lee et al. 1995). Black bars indicate conserved alpha-helix regions in the mutase domain. The species of bacterium, CM gene, and accession number of the aligned sequences, respectively: (1) Haemophilus influenzae, TyrA (P43902) (2) Escherichia coli, PheA (P07023) (3) Methanococcus jannaschii, PheA (2495875) (4) Streptomyces pristinaespiralis, Papb (1575338), (5) Erwinia herbicola, AroQ (P42517), (6) Meloidogyne javanica, NC30 (AF095949).

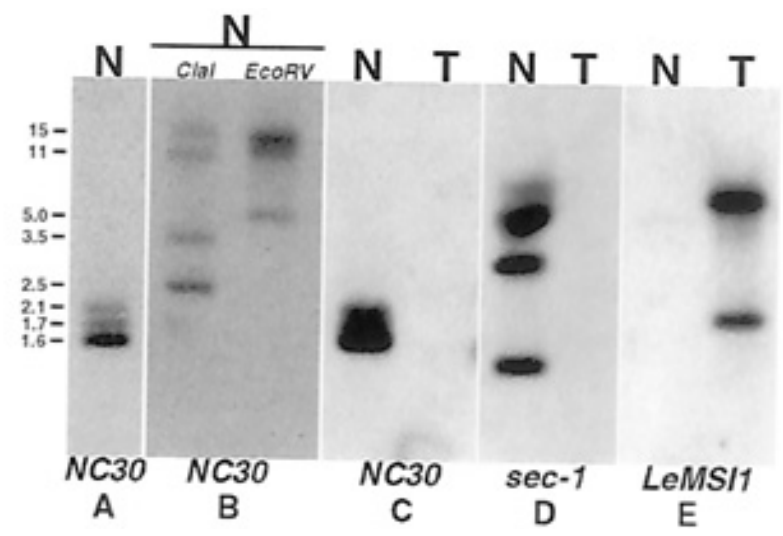

Fig. 2. Genomic Southern blots. $\mathrm{N}$ (nematode DNA) and $\mathrm{T}$ (tomato DNA) identify the DNA type in each lane of the blots. A, Nematode DNA digested with EcoRI and hybridized with the NC30 cDNA. B, Nematode DNA digested with ClaI in the first lane and EcoRV in the second lane and hybridized with an NC30 cDNA probe. C-E, Nematode and tomato DNA digested with EcoRI. DNA hybridized with $(\mathbf{C})$ NC30 cDNA, (D) sec-1 cDNA, (E) the tomato cDNA LeMSI1. Size of DNA markers given in kilobase pairs.

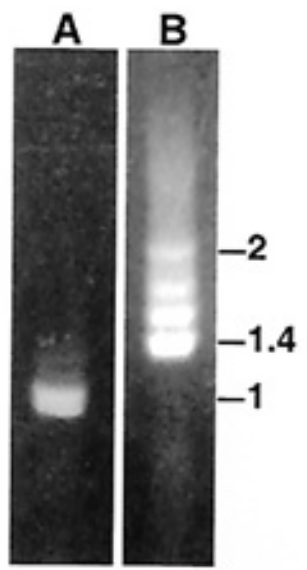

Fig. 3. Ethidium bromide-stained agarose gel of NC30 genomic DNA amplified by PCR (polymerase chain reaction). A, PCR products amplified from the $N C 30$ coding region. $\mathbf{B}, \mathrm{PCR}$ products from inverse PCR amplification of the flanking region of the NC30 genomic clone. Size of DNA markers given in kilobase pairs. 
Caenorhabditis elegans 3' splice site (TTTCAG; Blumenthal 1995), providing further evidence that $N C 30$ is of nematode origin.

Analysis of the $N C 30$ cDNA sequence revealed that it has features of a typical nematode mRNA. The NC30 cDNA was 718 bp long. A 22-bp SL sequence was identified at the $5^{\prime}$ end. This version of the SL sequence is only found in root-knot nematode mRNAs (Ray et al. 1994). A trans-splicing site (ATTTAG) was found at a location in the genomic clone that indicates that the NC30 mRNA is trans-spliced and that the presence of the SL sequence in the cDNA is not a PCR mis-

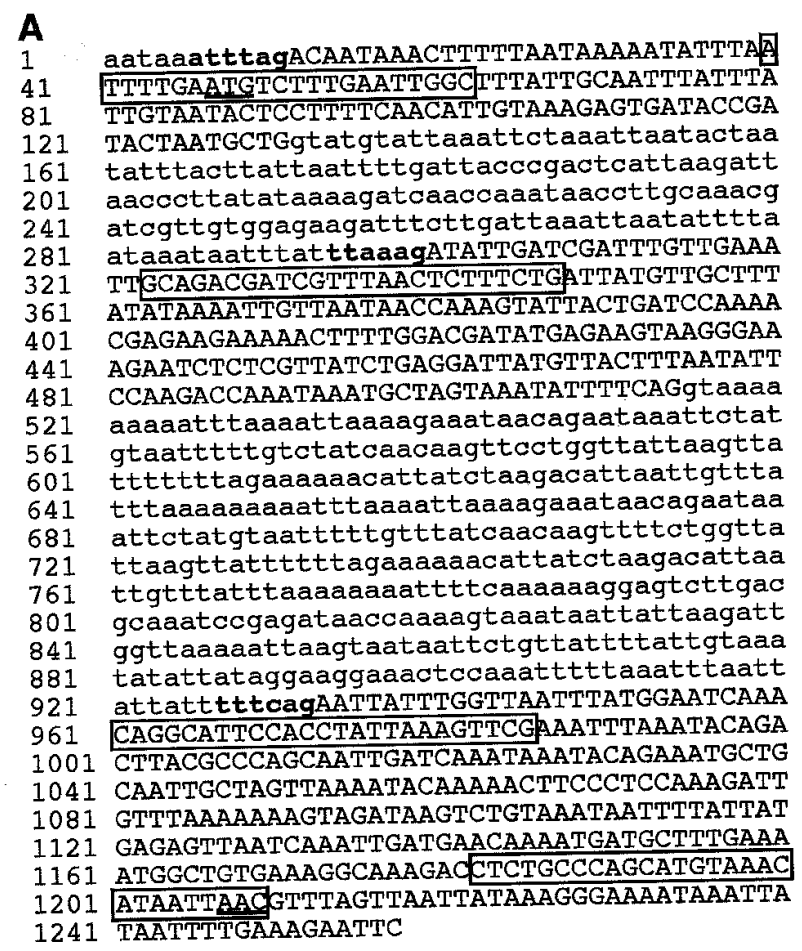

B

1 GGTTTAATTACCCAAGTTTAAGACAATAAACTTTTTAATA 41 AAAATATTTAATTTTGAATGTCTTTGAATTGGCTTTATTG 81 CAATTTATTTATTGTAATACTCCTTTTCAACATTGTAAAG 121 A GTGATACCGATACTAATGCTGATATTGATCGATTTGTTG 161 AAATTGCAGACGATCGTTTAACTCTTTCTGATTATGTTGC 201 TTTATATAAAATTGTTAATAACCAAAGTATTACTGATCCA 201 TTTATATAAAATTGTTAATAACCAAAGTATTACTGATCCA 281 GAAAGAATCTCTCGTTATCTGAGGATTATGTTACTTTAAT 321 ATTCCAAGACCAAATAAATGCTAGTAAATATTTTCAGAAT

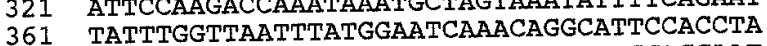
401 TTAAAGTTCGAAATTTAAATACAGACTTACGCCCAGCAAT 441 TGATCAAATAAATACAGAAATGCTGCAATTGCTAGTTAAA 481 ATACAAAAACTTCCCTCCAAAGATTGTTTAAAAAAAGTAG 521 ATAAGTCTGTAAATAATTTTATATGAGAGTTAATCAAAT 561 TGATGAACAAAATGATGCTTTGAAAATGGCTGTGAAAGGC 601 AAAGACETCTGCCCAGCATGTAAACATAATTAAGGTTTAG 641 TTAATTATAAAGGGAAAATAAATTATAATTTTGAAAGAAT 681 TCTGGGTTTCAAC (A) 25

Fig. 4. Nucleotide sequence of the $N C 30$ cDNA and genomic clone. A, Genomic sequence with the outron and introns shown in lowercase. Start and stop codons are underlined. PCR (polymerase chain reaction) primer sites for oligonucleotides NCM-3, NCM-4, NCM-5, NCM-2 are boxed. $3^{\prime}$ splice sites and the trans-splicing site are in bold. B, cDNA sequence with the SL, start and stop codons, and poly adenylation signal underlined. PCR primer sites for oligonucleotides NCM-1 and NCM-2 are boxed. GenBank accession numbers for the genomic clone and cDNA are AF095950 and AF095949, respectively. priming artifact. Following the SL sequence, there is a 35-bp 5 ' noncoding region before the ATG initiation codon and a 573-bp open reading frame that terminates with the TAA stop codon. On the $3^{\prime}$ end, the cDNA has a 60-bp 3' noncoding region containing a poly-A addition signal (AATAAA) followed by a 25-bp poly-A tail (Fig. 4B).

\section{CM multiple sequence alignment.}

The predicted protein sequence of NC30 was compared with the amino acid sequences of a variety of bacterial CMs (Fig. 1). On an amino acid level, CMs are very divergent from each other, but the amino acids that contribute to the active site of most bacterial CMs are conserved (Xia et al. 1993). We found that NC30 had 10 of the 12 highly conserved active site residues present in the E. coli CM (Fig. 1, sequence 2; Lee et al. 1995). It is important to note that there is no homology at the amino acid level between the predicted NC30 protein and eukaryotic CMs, presumably because of the latter's extreme evolutionary divergence (Xue and Lipscomb 1995).

While the primary amino acid sequence is not well conserved among CMs, the basic tertiary structure of the $E$. coli $\mathrm{CM}$ is conserved from bacteria to yeast (Xue and Lipscomb 1995). The three-dimensional structure of an E. coli CM monomer consists of three alpha-helices separated by two short spacer regions (Lee et al. 1995). Secondary structure prediction based on the NC30 sequence indicates that it also has the three conserved alpha-helix domains present in the bacterial CMs (Fig. 1). Considering that NC30 has both the highly conserved active site residues and the appropriate alpha-helix domains, it seems very likely that $N C 30$ encodes a nematode CM.

Functional tests of NC30 for CM activity.

Complementation of the CM-deficient E. coli strain JP2261 (Baldwin and Davidson 1981) was used to determine if NC30 had CM activity. Strain JP2261 contains no CM activity and has no prephenate dehydrogenase activity; therefore, it cannot grow on minimal medium without supplemental phenylalanine and tyrosine. When JP2261 was transformed with a plasmid containing the $N C 30$ coding region transcriptionally fused to the Trc promoter, the bacteria were able to grow in the absence of supplemental phenylalanine (Fig. 5). When the same strain of $E$. coli was transformed with only the plasmid vector, no rescue of the CM defect was observed (Fig. 5). This complementation experiment indicates that $N C 30$ encodes a functional CM.

$\mathrm{CM}$ enzyme assays were conducted on bacterial lysates made from E. coli JP2261 expressing NC30. The strain expressing NC30 contained measurable CM activity, but the same strain transformed with only the vector contained no measurable CM activity (Table 1). Since some CMs are feedback-regulated by aromatic amino acids, we tested the effect of aromatic amino acids on the nematode CM. There was no significant difference in CM activity among assays performed in the presence of each aromatic amino acid (Table 1). This result indicates that NC30 is in the class of $\mathrm{CMs}$ that are not feedback-regulated by aromatic amino acids. Since $N C 30$ encodes a functional nematode CM we renamed it MjCM-1 for Meloidogyne javanica chorismate mutase. 
Tissue localization of the nematode CM.

To determine which nematode organs express $M j C M$-1, we performed in situ RNA hybridization. When an MjCM-1 antisense riboprobe was hybridized to paraffin sections of nematode-infected roots, the antisense $M j C M-1$ probe specifically hybridized to a region in the nematode consistent in location with the basal cells of the esophageal glands (Fig. 6). Part of the anterior extension of the glands faintly hybridized to the probe, confirming that the signals were from the esophageal gland cells (Fig. 6B and C). Since the hybridization signals in Figure 6 varied in size, multiple glands might express $M j C M$ 1. We could not determine which gland(s) expressed $M j C M-1$ because the three glands' basal cells are closely packed together in early post-infection J2 nematodes (Bird and Saurer 1967), and there was not enough hybridization signal in the cytoplasmic extensions of the gland cells to determine where they connected to the esophageal lumen. No signal was obtained from the negative control, the $M j C M-1$ sense probe (Fig. 6D).

\section{DISCUSSION}

\section{Origin of the nematode $\mathrm{CM}$.}

Since it is unprecedented for an animal to have a CM, it is important to consider whether MjCM-1 is a nematode gene or the product of a bacterial or fungal endosymbiont or contaminant. First, it is unlikely that a nematode could have an endosymbiont in an esophageal gland since the invading microorganism would have to enter the nematode through its stylet. Because the stylet lumen is very narrow $(0.1 \mu \mathrm{m}$; Endo and Wergin 1988), this channel acts as a barrier preventing microbial invasion in a healthy nematode. Also, if $M j C M-1$ originated from a contaminant or endosymbiont, the gene copy number per genome would likely be different from that of a nematode gene. $M j C M-1$ has an equivalent copy number to the nematode gene $\sec -1$, indicating that $M j C M-1$ is likely not from a contaminating or symbiotic microorganism. While the MjCM-1 protein sequence may look similar to that of bacterial CMs, the cDNA and genomic sequence look like a typical nematode gene. The $M j C M-1$ cDNA has an SL sequence

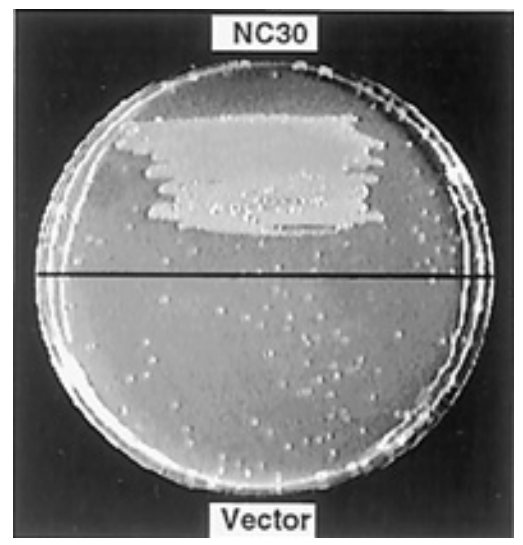

Fig. 5. Chorismate mutase (CM) complementation assay. A CMdeficient Escherichia coli strain transformed with a plasmid containing the $N C 30$ coding region was streaked on the top half of the petri dish (NC30). The same CM-deficient E. coli strain containing only the plasmid was streaked at the bottom half of the plate (Vector). Small dots spread throughout the dish are air bubbles. characteristic of nematode RNAs. While it is possible that the SL sequence could have been introduced as a PCR artifact, this is unlikely, since the $M j C M-1$ genomic clone has a transsplicing site in the appropriate position to yield the exact $M j C M-1$ cDNA sequence we obtained. The hybridization of the $M j C M-1$ cDNA to nematode genomic DNA and the presence of introns with nematode-like splice junctions in the genomic clone strongly support our conclusion that $\mathrm{MjCM}-1$ is a nematode gene. The resemblance of $M j C M-1$ to bacterial CMs may reflect past entry into the nematode genome by horizontal gene transfer. Alternatively, the nematode CM may have been conserved from a distant bacterial ancestor. A thorough phylogenetic analysis of CMs from a variety of bacteria, fungi, plants, and nematodes might help distinguish between these two possibilities.

\section{Potential roles of a nematode $\mathrm{CM}$.}

The importance of CMs in plants and microbes may indicate that $M j C M-1$ plays a critical role in the biology of $M$. javanica. There are two places where $M j C M-1$ may function: (i) CM may be secreted from the gland cell and move back into the intestine; or (ii) CM may be secreted from the nematode into the plant cell. It is unlikely that the nematode makes this enzyme for metabolic functions within its own body, because it can obtain all its essential amino acids from the plant. Also, since the shikimate pathway is commonly assumed to be absent in animals (Roberts et al. 1998; Stryer 1988) one would expect that a nematode CM could not play a biosynthetic role within the nematode. While the evidence for the presence or absence of the shikimate pathway in nematodes is scarce, amino acid deprivation experiments have been used to determine if nematodes have the complete pathway. While it is impossible to conduct this type of analysis on obligate parasites like the root-knot nematode, nutritional studies on free-living and non-obligate parasitic nematodes show that aromatic amino acids are an essential dietary requirement for nematode growth and reproduction (Vanfleteren 1978). While this does not conclusively prove the absence of the shikimate pathway in nematodes, it does indicate that life-sustaining levels of aromatic amino acids are not produced. Consistent with these observations, no enzymes of the shikimate pathway, including $\mathrm{CM}$, have yet been identified in the ongoing Caenorhabditis elegans sequencing project. Finally, the observation that the $M j C M-1$ gene is expressed only in nematode esophageal glands, organs whose primary function has long been associated with parasitism, suggests that the most likely role of the

Table 1. Effect of aromatic amino acids on $\mathrm{NC} \mathrm{CM}^{\mathrm{a}}$

\begin{tabular}{lcc}
\hline Plasmid & Amino acid & CM activity \\
\hline pTRC99a & None & None detected \\
pTRC99a:NC30 & None & $88.7 \pm(1.7)$ \\
pTRC99a:NC30 & Tyrosine & $88.8 \pm(0.7)$ \\
pTRC99a:NC30 & Phenylalanine & $87.8 \pm(0.9)$ \\
pTRC99a:NC30 & Tryptophan & $84.5 \pm(2.9)$ \\
\hline
\end{tabular}

${ }^{a}$ Activity of CM (chorismate mutase) measured in desalted crude protein extracts of Escherichia coli JP2261 transformed with plasmid pTRC99a or pTrc99a expressing NC30. The concentration of each amino acid in the assay was $0.5 \mathrm{mM}$. CM activities are expressed in nmol prephenate formed $\cdot \min ^{-1} \cdot \mathrm{mg}$ protein ${ }^{-1}$ with the average and the standard error for three replications shown. A $t$ test showed no significant difference between the treatment means $(P>0.05)$. 
MjCM-1 protein is to aid the nematode in the establishment of a feeding relationship with the plant.

Root-knot nematodes have a broad host range, indicating that they alter basic metabolic processes present in most, if not all, higher plants. The shikimate pathway might be a primary metabolic pathway that the nematode is manipulating. We hypothesize that the nematode $\mathrm{CM}$ is injected into the plant cytosol, where it accelerates the conversion of chorismate to prephenate in an unregulated manner, consequently altering the synthesis of plant CDCs. This alteration of CDCs then plays some role(s) in allowing the nematode to establish a parasitic association with the plant.

While we have shown that $M j C M-1$ encodes an esophageal gland-specific CM, our data do not directly show that the nematode $\mathrm{CM}$ is secreted or injected into plant cells. However, the predicted protein sequence of $\mathrm{MjCM}-1$ has a signal sequence motif, suggesting that it may be secreted. In addition, the MjCM-1 substrate, chorismate, is a plant primary metabolite that is synthesized intracellularly. This suggests that the nematode CM must be injected to have an effect on the plant. High resolution immunolocalizations could be used to verify this suggestion. The observation that the MjCM-1 protein is not feedback-regulated by the aromatic amino acids suggests that if the nematode CM were introduced into a plant cell environment its activity would not be subject to plant regulation. However, to determine if the nematode CM is unregulatable it should be tested with a variety of plant phenolic compounds that are known to modulate plant CM activity (Gilchrist and Kosuge 1980).
The exact consequence of injecting a nematode $\mathrm{CM}$ into a plant cell is difficult to predict because the subcellular location of the enzymes of the shikimate pathway is unclear. Although the complete shikimate pathway is known to exist in plastids, some key enzymes in this process have not been found in the cytoplasm (Schmid and Amrhein 1995; Weaver and Herrmann 1997). Interestingly, CM is one of the enzymes in the shikimate pathway that has been consistently shown to have a cytoplasmic isozyme (Eberhard et al. 1996a, 1996b) The presence of such cytoplasmic CMs suggests that injection of exogenous nematode CM could have an effect on plants. The nature of this effect could differ depending on whether the cytoplasmic shikimate pathway in plants is complete or whether it would compete for a common plastid chorismate source. The effect of a nematode CM would also depend on what CDCs are formed by the cytosolic branch of the shikimate pathway. Since there are so many unknown factors in how the two pathways interact and what they form, we can only speculate that a large change in the profile of CDCs could occur if a nematode CM were injected into a plant cell. Since CDCs are critical precursors for cell wall formation, plant hormone biosynthesis, and synthesis of plant defense compounds, alteration of these compounds could drastically affect many properties of a developing plant cell. In addition to the direct alteration of plant cell structure, MjCM-1induced increase of cytosolic CDCs could provide an abundant supply of food for a growing nematode.

In summary, we have developed a novel method to isolate tissue-specific cDNA clones from any dissectable nematode
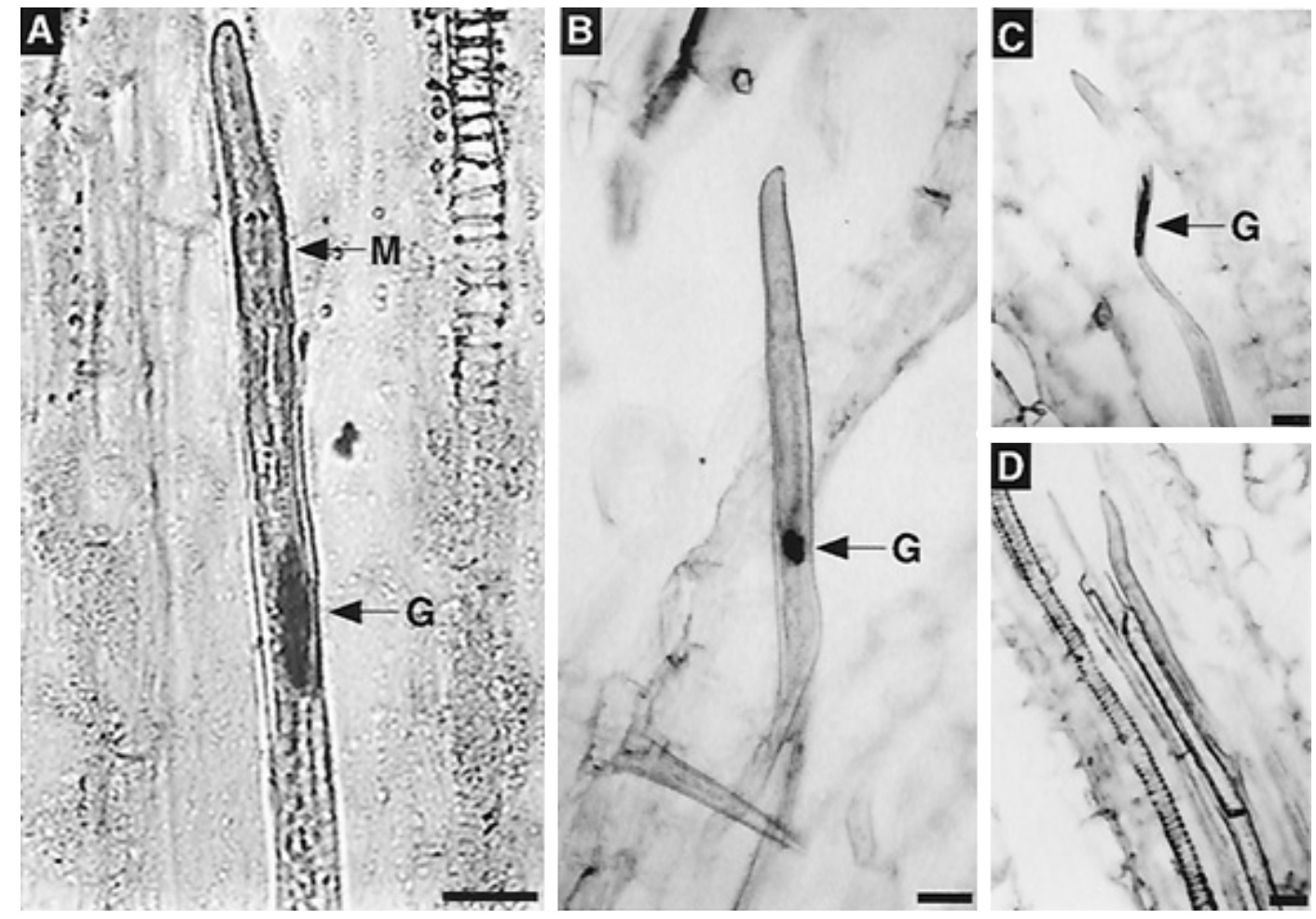

Fig. 6. Localization of $M j C M-1$ RNA in post-infection J2 nematodes. A-D, RNA in situ hybridization of the $M j C M$ - 1 probe to post-infection J2 nematodes that were in the tomato root 5 days or less. A, B, and $\mathbf{C}$, Sections hybridized with $M j C M-1$ antisense digoxigenin-labeled riboprobe. D, Sections hybridized with an MjCM-1 sense digoxigenin-labeled riboprobe. All hybrids were detected with an alkaline phosphatase-conjugated anti-digoxigenin antibody followed by staining for alkaline phosphatase. Arrows indicate hybridization signals in the nematodes gland(s). M: metacorpus; G: esophageal gland(s). Scale bars $=20 \mathrm{~mm}$. 
region. This approach now makes it possible to conduct a molecular analysis of phytoparasitic nematodes during all phases of their life cycle. Using this approach, we have isolated the first animal CM gene and have demonstrated that it is expressed specifically in nematode esophageal glands. If this nematode $\mathrm{CM}$ plays a critical role in nematode parasitism on plants, then blocking its activity may be a way of controlling these devastating pathogens.

\section{MATERIALS AND METHODS}

\section{Nematode culture and dissection.}

Nematodes (Meloidogyne javanica (Treub) Chitwood) were cultured as described by Lambert et al. (1992). Roots of tomato seedlings (Lycopersicon esculentum Mill. UC82) were inoculated with 25 preparasitic $\mathrm{J} 2$ nematodes as described by Ho et al. (1992), and incubated in a growth chamber with continuous light at 22 to $25^{\circ} \mathrm{C}$. To collect post-infection $\mathrm{J} 2$ nematodes, infected roots were torn in half and nematodes were removed with an electroetched tungsten knife (Cutter 1967). Individual nematodes were transferred to drops of $0.5 \%$ carboxymethylcellulose on standard microscope slides, then dried at $100^{\circ} \mathrm{C}$ with a heat block. Nematodes were dissected with the aid of an inverted compound microscope fitted with a coarse micromanipulator holding a tungsten knife. To remove the esophageal gland region, J2 nematodes were cut about 90 and $170 \mu \mathrm{m}$ from the anterior end of the nematode. The gland region was transferred to a $0.2-\mathrm{ml}$ PCR tube with a $20-\mu \mathrm{m}$-diameter-tip glass needle. Tail regions were isolated by cutting about 275 and $325 \mu \mathrm{m}$ from the anterior end of the nematode.

\section{cDNA amplification and library construction.}

RNA was extracted from nematode tissue in $10 \mu$ of proteinase K solution (0.1 M Tris- $\mathrm{HCl}$ (pH 8.0), $12.5 \mathrm{mM}$ EDTA, $0.15 \mathrm{M} \mathrm{LiCl}, 1 \%$ SDS, $1 \mathrm{mM}$ DTT (dithiothreitol), $800 \mathrm{ng}$ of 5S RNA, $2 \mathrm{mg} \mathrm{ml}^{-1}$ proteinase $\mathrm{K}$ ) for $1 \mathrm{~h}$ at $37^{\circ} \mathrm{C}$. After extraction, $15 \mu$ of DEPC (diethyl pyrocarbonate)-treated $\mathrm{H}_{2} \mathrm{O}$ was added to the proteinase $\mathrm{K}$ digest and the RNA was denatured at $100^{\circ} \mathrm{C}$ for $2 \mathrm{~min}$.

Strepavidin-coated beads (Dynabeads M-280; Dynal, Lake Success, NY) were prepared by washing $0.41-\mathrm{mg}$ beads with $50 \mu \mathrm{l}$ of $2 \times$ binding buffer (20 mM Tris- $\mathrm{HCl}$ [pH 7.5], $1.0 \mathrm{M}$ $\mathrm{LiCl}, 2 \mathrm{mM}$ EDTA). The beads were resuspended in $50 \mu \mathrm{l}$ of $2 \times$ binding buffer and 200 pmol of biotinylated oligonucleotide A, allowed to bind for $15 \mathrm{~min}$ at room temperature, then washed three times with $50 \mu \mathrm{l}$ of wash buffer $(10 \mathrm{mM}$ Tris$\mathrm{HCl}$ [pH 7.5], $0.15 \mathrm{M} \mathrm{LiCl}, 1 \mathrm{mM}$ EDTA). The beads were resuspended in $25 \mu \mathrm{l}$ of $2 \times$ binding buffer and added to the freshly denatured RNA.

The poly $\mathrm{A}^{+}$nematode RNA was allowed to hybridize to the beads for $15 \mathrm{~min}$ at room temperature. The beads were washed with $50 \mu \mathrm{l}$ of $2.5 \times$ Reverse Transcription Buffer (GibcoBRL, Grand Island, NY). Twenty microliters of reverse transcription mix (1× ReverseTranscription Buffer, $10 \mathrm{mM}$ DTT, $0.5 \mathrm{mM}$ dNTP, 200 units SuperScript II [GibcoBRL]) was added to the beads, and the reaction was incubated at $37^{\circ} \mathrm{C}$ for $1 \mathrm{~h}$. The beads were washed with $50 \mu \mathrm{l}$ of $1 \times$ Klentaq reaction buffer (Clontech, Palo Alto, CA) then resuspended in $50 \mu \mathrm{l}$ of PCR mix (10 pmol each of oligonucleotide $\mathrm{B}$ and oligonucleotide C, $0.2 \mathrm{mM}$ dNTP stock, $1 \times$ Klentaq reaction buffer, and $1 \mu \mathrm{l}$ of Klentaq enzyme [Clontech]). Nematode cDNA was amplified by PCR by heating to $94^{\circ} \mathrm{C}$ for $30 \mathrm{~s}$, followed by 35 cycles of $94^{\circ} \mathrm{C}(30 \mathrm{~s}), 61^{\circ} \mathrm{C}(30 \mathrm{~s})$, $68^{\circ} \mathrm{C}(3 \mathrm{~min})$, then a single cycle at $68^{\circ} \mathrm{C}(30 \mathrm{~min})$.

Amplified cDNA was purified with a Chromaspin-200 column (Clontech). The purified cDNA was cloned into the pDirect plasmid vector with the PCR-Direct cloning system (Clontech) and transformed into ultracompetent E. coli XL2Blue MRF' (Stratagene, La Jolla, CA).

\section{Selection of esophageal gland-specific cDNAs.}

All cDNA used for probe synthesis was prepared by the PCR method described above. Cells containing the cDNA library were grown to a density of 1,000 CFU per plate and transferred to nitrocellulose membranes (Sambrook et al. 1989). Preparasitic J2 nematode cDNA was random primed labeled with $\alpha{ }^{-32} \mathrm{P}-\mathrm{dCTP}$ with a Prime-it II kit (Stratagene). Colonies that hybridized with the probes were detected by standard protocols (Sambrook et al. 1989). Nonhybridizing colonies were selected and the presence of inserts verified by PCR with 10 pmol each of primers M13-F and M13-R. The cDNA plasmid inserts were amplified as described above. Two duplicate dot blots were prepared following published procedures (Anderson and Young 1985). Each membrane was hybridized to a cDNA probe derived from either the gland or tail region of post-infection $\mathrm{J} 2$ nematodes.

\section{Oligonucleotides.}

All oligonucleotides were synthesized by Genemed Synthesis (South San Francisco, CA).

Oligo A: 5'-biotin-GGCGCCCTGGTTCGGCCCACATT GACGTCGACTATCCA(T) $25-3^{\prime}$

Oligo B: 5'-CTGGTTCGGCCCACATTGACGTCGACTA TCCA-3'

Oligo C: $5^{\prime}$-CTCGCTCGCCCAGGTTTAATTACCCAAG TTTAAG-3'

M13-F: 5'-TCACGACGTTGTAAAACGACGG-3'

M13-R: 5'-TTCACACAGGAAACAGCTATG-3'

NCM-1: 5'-AGTCCATGGGTGATACCGATACTAATGCT GATATT-3'

NCM-2: 5'-CATCCATGGTTAATTATGTTTACATGCTG GGCAGAG-3'

NCM-3: 5'-ATTTTGAATGTCTTTGAATTGGC-3'

NCM-4: 5'-CAGAAAGAGTTAAACGATCGTCTGC-3'

NCM-5: 5'-CAGGCATTCCACCTATTAAAGTTCG-3'

Sec1-A: 5'-GGGAAGCGCAATCATTCTA-3'

Sec1-B: 5'-GTCCGACATGACTACCGGA-3'

\section{DNA sequence analysis.}

All cDNA clones were sequenced at the University of California Berkeley DNA sequencing facility. BLASTP2 was used for sequence similarity searches (Altschul et al. 1997). CM protein sequences were aligned with CLUSTAL W, version 1.6 (Thompson et al. 1994). Secondary structure prediction was calculated for the aligned sequences with the Predict Protein package (Rost and Sanders 1995).

\section{CM complementation.}

The NC30 coding region minus the putative signal sequence was amplified by PCR with primers NCM-1 and NCM-2, which have $\mathrm{NcoI}$ restriction sites, at $94^{\circ} \mathrm{C}(30 \mathrm{~s}),\left(94^{\circ} \mathrm{C}[30 \mathrm{~s}]\right.$, 
$51^{\circ} \mathrm{C}$ [30 s], $68^{\circ} \mathrm{C}$ [ $1 \mathrm{~min}$ ], 30 cycles $)$, and $68^{\circ} \mathrm{C}$ (30 min). The resulting PCR product was digested with $\mathrm{NcoI}$, ligated into the NcoI site of plasmid pTrc99a (Pharmacia, Piscataway, $\mathrm{NJ}$ ), and then transformed into E. coli JP2261 (aroF363, pheO352, pheA365, tyrA382, thi-1, lac, tsx-358, rpsL712, $x y l$; Baldwin and Davidson 1981). Transformed E. coli cells were plated on M9 minimal medium supplemented with 100 $\mu \mathrm{g} \mathrm{ml}^{-1}$ ampicillin, 5\% (wt/vol) glucose, $30 \mathrm{mg} \mathrm{l}^{-1}$ tyrosine, $5 \mathrm{mg} \mathrm{l}^{-1}$ thiamine and $40 \mu \mathrm{l}$ of $100 \mathrm{mM}$ IPTG (isopropyl- $\beta$ D-thiogalactopyranoside).

\section{CM enzyme assay.}

When the cultures of $E$. coli expressing $N C 30$ reached an OD of 0.5 to 0.6 , IPTG was added to a final concentration of 1 $\mathrm{mM}$ and the culture was allowed to grow $2 \mathrm{~h}$ more at $37^{\circ} \mathrm{C}$. The cells were concentrated by centrifugation at $4^{\circ} \mathrm{C}$ and lysed by the freeze-thaw method, and the protein extract was desalted with an NAP-10 column (Pharmacia). The extracts were assayed for $\mathrm{CM}$ activity by the enol-borate complex method (Gilchrist and Connelly 1987).

\section{Southern blots.}

Preparasitic J2 nematodes were collected from hydroponic nematode cultures (Lambert et al. 1992). Plant debris was removed by allowing the nematodes to crawl through 10 layers of Kimwipes as described previously (Ho et al. 1992). One hundred microliters of packed nematodes was frozen in liquid nitrogen, then the nematodes were broken into small pieces in a tissue pulverizer (Fisher Scientific, Pittsburgh, PA). The frozen nematode fragments were mixed with $1 \mathrm{ml}$ of the same proteinase $\mathrm{K}$ solution used in RNA preparation and incubated at $37^{\circ} \mathrm{C}$ for $1 \mathrm{~h}$. The DNA was phenol/chloroform extracted, then precipitated with ethanol. The resuspended genomic DNA was treated with RNase $\left(10 \mu \mathrm{g} \mathrm{ml}^{-1}\right)$ at $37^{\circ} \mathrm{C} 1 \mathrm{~h}$, then dialyzed in TE (10 mM Tris- $\mathrm{HCl}$ [pH 7.5], $1 \mathrm{mM}$ EDTA) overnight at $4^{\circ} \mathrm{C}$. Ten micrograms of nematode genomic DNA was used per lane on each Southern blot. The tomato genomic DNA (a gift from Valerie M. Williamson, University of California at Davis) was extracted from Lycopersicon esculentum Mill. UC82. Twenty micrograms of DNA per lane was used for each Southern blot.

The NC3O cDNA was amplified by PCR from the original plasmid with oligonucleotides NCM-2 and NCM-3. The sec-1 cDNA was amplified by PCR from preparasitic $\mathrm{J} 2$ nematode cDNA (described above) with oligonucleotides Sec1A and Sec1B. The tomato cDNA LeMSI1 (Ach et al. 1997) was amplified by PCR with oligonucleotides M13F and M13R. All PCR products used for probes were purified with a Chromaspin 100 column (Clontech), then random primed labeled with ${ }^{32} \mathrm{P}$-dCTP with the Prime-it II kit (Stratagene). The probes $\left(2.5 \times 10^{6} \mathrm{cmp} \mathrm{ml}^{-1}\right)$ were hybridized to the filters, and hybridization signals were detected by standard protocols (Sambrook et al. 1989). Blots were typically exposed to X-ray film for 3 days at $-80^{\circ} \mathrm{C}$ with one intensifying screen.

\section{Isolation of the $N C 30$ genomic clone.}

Oligos NCM-2 and NCM-3 were used to PCR amplify the coding region from genomic DNA. Oligos NCM-4 and NCM5 were used to amplify the genomic DNA flanking the NC3O coding region by inverse PCR of EcoRI-cut genomic DNA with the procedure described previously (Ochman et al. 1990).
The genomic DNA was isolated as described above and the PCR conditions were the same as those for the NC3O cDNA amplification. All amplified genomic fragments were cloned into a plasmid vector with the TOPO cloning kit (Invitrogen, Carlsbad, CA).

\section{In situ hybridization.}

The probe template was prepared by PCR amplification of the $M j C M-1$ plasmid with 10 pmol each of M13-F and M13-R primers, as described above. After PCR, T4 DNA polymerase $(10 \mathrm{U})$ and dNTPs (final concentration $1 \mathrm{mM}$ ) were added, and the reaction incubated for $30 \mathrm{~min}$ at $37^{\circ} \mathrm{C}$. The cDNA insert was purified with a Chromaspin-200 column. Digoxigenin-labeled RNA probes were synthesized from $300 \mathrm{ng}$ of purified template with the T7 and T3 AmpliScribe High Yield Transcription Kits (Epicentre Technologies, Madison WI) with the following nucleotide concentrations: $7.5 \mathrm{mM}$ GTP, $7.5 \mathrm{mM}$ ATP, $7.5 \mathrm{mM}$ CTP, $5 \mathrm{mM}$ UTP, $3 \mathrm{mM}$ dig-11-UTP (Boehringer Mannheim, Indianapolis, IN). Labeled RNA was purified with a Chromaspin-200 column. The RNA probe was hydrolyzed to a length of approximately 150 to $300 \mathrm{bp}$ (Angerer and Angerer 1992). The probe was used at a concentration of $1 \mathrm{ng} \mu \mathrm{l}^{-1}$.

Excised nematode-infected root tips were fixed in FAA (3.7\% formaldehyde, $50 \%$ ethanol, $5 \%$ glacial acetic acid) and paraffin embedded (Schichnes et al., in press), and 10- $\mu \mathrm{m}$ sections were cut on a rotary microtome. The paraffin sections were processed and hybridized to the $M j C M-1$ riboprobes according to published protocols (Jackson 1992). The hybridized probe was detected following the protocol of Coen (Coen et al. 1990) with slight modifications (Ruzin, in press). Labeled cells were examined with a Zeiss Axiophot microscope. Images were either captured with a low-light cooled color CCD camera (Davidson Optronics, West Covina CA) or photographed with Ektachrome 160T $35 \mathrm{~mm}$ color slide film (Eastman Kodak, Rochester, NY).

\section{ACKNOWLEDGMENTS}

We thank Kristen Shepard, Jo Anne Welsch, and George Theodoris for their critical review of the manuscript. We would also like to extend our gratitude to Steve Ruzin (Biological Imaging Facility in the College of Natural Resources at the University of California Berkeley ) for his help with plant microtechnique and microscopy. We are grateful to A. J. Pittard (University of Melbourne) for the gift of the E. coli strain JP2261 and to Valerie M. Williamson (University of California, Davis) for providing the tomato genomic DNA. This work was supported by grant numbers 95-37304-2330 and 97-35302-4329 from the United States Department of Agriculture National Research Initiative Competitive Grants Program.

\section{LITERATURE CITED}

Ach, R. A., Taranto, P., and Gruissem, W. 1997. A conserved family of WD-40 proteins binds to the retinoblastoma protein in both plants and animals. Plant Cell 9:1595-1606.

Altschul, S. F., Madden, T. L., Schäffer, A. A., Zhang, J., Zhang, Z., Miller, W., and Lipman, D. J. 1997. Gapped BLAST and PSI-BLAST: A new generation of protein database search programs. Nucleic Acids Res. 25:3389-3402.

Anderson, M. L. M., and Young, B. D. 1985. Quantitative filter hybridization. Pages 73-111 in: Nucleic Acid Hybridization: A Practical Approach. B. D. Hames and S. J. Higgins, eds. IRL Press, Oxford.

Angerer, L. M., and Angerer, R. C. 1992. In situ hybridization to cellular RNA with radiolabelled RNA probes. Pages 15-32 in: In Situ Hybridi- 
zation: A Practical Approach. D. G. Wilkinson, ed. IRL Press, Oxford.

Bairoch, A., Bucher, P., and Hofmann, K. 1997. The PROSITE database, its status in 1997. Nucleic Acids Res. 25:217-221.

Baldwin, G. S., and Davidson, B. E. 1981. A kinetic and structural comparison of chorismate mutase/prephenate dehydratase from mutant strains of Escherichia coli K12 defective in the PheA gene. Arch. Biochem. Biophys. 211:66-75.

Bird, A. F., Downton, W. S. J., and Hawker, J. S. 1974. Cellulase secretion by second stage larvae of the root-knot nematode (Meloidogyne javanica). Marcellia 38:165-169.

Bird, A. F., and Saurer, W. 1967. Changes associated with parasitism in nematodes. II. Histochemical and microspectrophotometric analyses of preparasitic and parasitic larvae of Meloidogyne javanica. J. Parasitol. 53:1262-1269.

Blumenthal, T. 1995. Trans-splicing and polycistronic transcription in Caenorhabditis elegans. Trends Genet. 11:132-136.

Coen, E. S., Romero, J. M., Doyle, S., Elliott, R., Murphy, G., and Carpenter, R. 1990. floricaula: A homeotic gene required for flower development in Antirrhinum majus. Cell 63:1311-1322.

Cutter, E. G. 1967. Surgical techniques in plants. Pages 623-634 in: Methods in Developmental Biology. F. H. Wilt and N. K. Wessells, eds. Crowell, New York.

Doncaster, C. C. 1971. Feeding in plant parasitic nematodes: Mechanisms and behavior. Pages 137-157 in: Plant Parasitic Nematodes. Vol. 2. B. M. Zucherman, ed. Academic Press, New York

Dropkin, V. H. 1963. Cellulase in phytoparasitic nematodes. Nematologica 9:444-454.

Eberhard, J., Bischoff, M., Raesecke, H.-R., Amrhein, N., and Schmid, J. 1996a. Isolation of a cDNA from tomato coding for an unregulated, cytocolic chorismate mutase. Plant Mol. Biol. 31:917-922.

Eberhard, J. E., Ehrier, T. T., Epple, P., Felix, G., Raesecke, H.-R., Amrhein, N., and Schmid, J. 1996b. Cytosolic and plastidic chorismate mutase isozymes from Arabidopsis thaliana: Molecular characterization and enzymatic properties. Plant J. 10:815-821.

Endo, B. Y., and Wergin, W. P. 1988. Ultrastructure of the second-stage juvenile of the root-knot nematode, Meloidogyne incognita. Proc. Helminthol. Soc. Wash. 55:286-316.

Gilchrist, D. G., and Connelly, J. A. 1987. Chorismate mutase from mung bean and sorghum. Pages 450-463 in: Methods in Enzymology. S. Kaufman, ed. Academic Press, Orlando, FL.

Gilchrist, D. G., and Kosuge, T. 1980. Aromatic amino acid biosynthesis and its regulation. Pages 507-531 in: The Biochemistry of Plants. Vol. 5. B. J. Miflin, ed. Academic Press, New York.

Ho, J.-Y., Weide, R., Ma, H. M., Wordragen, M. F., Lambert, K. N., Koornneef, M., Zabel, P., and Williamson, V. M. 1992. The root-knot nematode resistance gene $(\mathrm{Mi})$ in tomato: Construction of a molecular linkage map and identification of dominant cDNA markers in resistant genotypes. Plant J. 2:971-982.

Hussey, R. S. 1989. Disease-inducing secretions of plant-parasitic nematodes. Annu. Rev. Phytopathol. 27:123-141.

Jackson, D. 1992. In situ hybridization in plants. Pages 163-174 in: Molecular Plant Pathology: A Practical Approach. S. J. Gurr, M. McPherson, and D. J. Bowles, eds. IRL Press, Oxford.

Lambert, K. N., Tedford, E. C., Caswell, E. P., and Williamson, V. M. 1992. A system for continuous production of root-knot nematode juveniles in hydroponic culture. Phytopathology 82:512-515.

Lee, A. Y., Karplus, P. A., Ganem, B., and Clardy, J. 1995. Atomic structure of the buried catalytic pocket of Escherichia coli chorismate mutase. J. Am. Chem. Soc. 117:3627-3628.

Martin, S. A. M., Thompson, F. J., and Devaney, E. 1995. The construction of spliced leader cDNA libraries from the filarial nematode Brugia pahangi. Mol. Biochem. Parasitol. 70:241-245.
Nakai, K., and Kanehisa, M. 1992. A knowledge base for predicting protein localization sites in eukaryotic cells. Genomics 14:897-911.

Nilsen, T. W. 1993. Trans-splicing of nematode premessenger RNA. Annu. Rev. Microbiol. 47:413-440.

Ochman, H., Medhora, M. M., Garza, D., and Hartl, D. L. 1990. Amplification of flanking sequences by inverse PCR. Pages 219-227 in: PCR Protocols: A Guide to Methods and Applications. M. A. Innis, D. H. Gelfand, J. J. Sninsky, and T. J. White, eds. Academic Press, San Diego, CA.

Ray, C., Abbott, A. G., and Hussey, R. S. 1994. Trans-splicing of a Meloidogyne incognita mRNA encoding a putative esophageal gland protein. Mol. Biochem. Parasitol. 68:93-101.

Roberts, F., Roberts, C. W., Johnson, J. J., Kyle, D. E., Krell, T., Coggins, J. R., Coombs, G. H., Milhous, W. K., Tripori, S., Ferguson, D. J. P., Chakrabarti, D., and McLeod, R. 1998. Evidence for the shikimate pathway in apicomplexan parasites. Nature 393:801-805.

Romero, R. M., Roberts, M. F., and Phillipson, J. D. 1995. Chorismate mutase in microorganisms and plants. Phytochemistry 40:1015-1025.

Rost, B., and Sanders, C. 1995. Progress of 1D protein structure prediction at last. Proteins Struct. Funct. Genet. 23:295-300.

Ruzin, S. E. Plant Microtechnique and Microscopy. Oxford University Press, Oxford. (In press.)

Sambrook, J., Fritsch, E. F., and Maniatis, T. A. 1989. Molecular Cloning: A Laboratory Manual. 2nd ed. Cold Spring Harbor Laboratory, Cold Spring Harbor, NY.

Sasser, J. N. 1980. Root-knot nematodes: A global menace to crop production. Plant Dis. 64:36-41.

Schichnes, D., Nemson, J., Sohlberg, L., Ruzin, S. E. Microwave protocols for paraffin microtechnique and in situ localization in plants. Microsc. Microanal. (In press.)

Schmid, J., and Amrhein, N. 1995. Molecular organization of the shikimate pathway in higher plants. Phytochemistry 39:737-749.

Smant, G., Stokkermans, J. P. W. G., Yan, Y., de Boer, J. M., Baum, T. J., Wang, X., Hussey, R. S., Gommers, F. J., Henrissat, B., Davis, E. L., Helder, J., Schots, A., and Bakker, J. 1998. Endogenous cellulases in animals: Isolation of $\beta-1,4$-endoglucanase genes from two species of plant-parasitic cyst nematodes. Proc. Natl. Acad. Sci. USA 95:49064911.

Strack, D. 1997. Phenolic Metabolism. Pages 387-416 in: Plant Biochemistry. P. M. Dey and J. B. Harborne, eds. Academic Press, New York.

Stryer, L. 1988. Biochemistry. 3rd ed. W. H. Freeman, New York.

Thompson, J. D., Higgins, D. G., and Gibson, T. J. 1994. CLUSTAL W: Improving the sensitivity of progressive multiple sequence alignment through sequence weighting, position-specific gap penalties and weight matrix choice. Nucleic Acids Res. 22:4673-4680.

Vanfleteren, J. R. 1978. Axenic culture of free-living, plant-parasitic, and insect-parasitic nematodes. Annu. Rev. Phytopathol. 16:131-157.

von Heijne, G., and Abrahmsén, L. 1989. Species-specific variation in signal peptide design: Implications for protein secretion in foreign hosts. FEBS Lett. 244:439-446.

Weaver, L. M., and Herrmann, K. M. 1997. Dynamics of the shikimate pathway in plants. Trends Plant Sci. 2:346-351.

Williamson, V. M., and Hussey, R. S. 1996. Nematode pathogenesis and resistance in plants. Plant Cell 8:1735-1745.

Xia, T., Song, J., Zhao, G., Aldrich, H., and Jensen, R. A. 1993. The aro $Q$-encoded monofunctional chorismate mutase (CM-F) protein is a periplasmic enzyme in Erwinia herbicola. J. Bacteriol. 175:47294737.

Xue, Y., and Lipscomb, W. N. 1995. Location of the active site of allosteric chorismate mutase from Saccharomyces cerevisiae, and comments on the catalytic and regulatory mechanisms. Proc. Natl. Acad. Sci. USA 92:10595-10598. 